\title{
HIV/AIDS Related Knowledge and Attitudes in Navakholo Community, Kenya
}

\author{
Mukhwana Eugine Sundays ${ }^{1, *}$ Ayuku D $\mathbf{O}^{2}$, Baliddawa $\mathbf{J}^{2}$ \\ ${ }^{1}$ Masinde Muliro University of Science and Technology, Kenya \\ ${ }^{2}$ Department of Behavioural Science, Moi University, School of Medicine, Kenya
}

Copyright $(\subset 2016$ by authors, all rights reserved. Authors agree that this article remains permanently open access under the terms of the Creative Commons Attribution License 4.0 International License

\begin{abstract}
The purpose of this study was to assess levels of knowledge on HIV/AIDS, attitudes towards PLWHAs and programs to prevent HIV infection of community members of Navakholo in Western Kenya. This was a cross-sectional study that used quantitative data collection methods. Three hundred and eighty four (384) Household Heads randomly selected from the study area were interviewed using a questionnaire. Data obtained was analyzed using SPSS computer software program Version 18. ANOVA was used to check for probable differences between core variables of HIV/AIDS knowledge, attitude, and perceptions against gender, education and age. Study findings revealed that the level of knowledge was high $(92 \%$ of the respondents had high levels of knowledge, although some gaps in knowledge and misconceptions about HIV infection and AIDS were also evident). Attitudes towards PLWHAs and programs to prevent HIV infection were varied with $34 \%$ of the respondents displaying stigmatizing attitudes. The study concluded that gaps in knowledge, misconceptions about modes of HIV transmission as well as negative attitudes are an impediment to the community's efforts to control the spread of AIDS. The study recommends intensive HIV/AIDS education to members of the community to fill the gaps in knowledge and to correct the misconceptions noted. The education should be tailored to help improve on attitudes towards PLWHAs and programs to prevent HIV infection.
\end{abstract}

Keywords HIV/AIDS, Knowledge, Attitudes and Community

\section{Introduction}

Globally, an estimated 35.3 million people were living with HIV in 2012[1]. Sub-Saharan Africa was the region most affected by HIV, accounting for 25,000,000 people living with HIV, 1,600,000 estimated new HIV infections, and 1,200,000 estimated HIV deaths in 2012 [1,3\&4]. Kenya is listed among countries highly devastated by the AIDS epidemic [1]. The first case of HIV was reported in Kenya in the 1980"s [7]. The disease has since spared to almost all parts of the country with Nyanza Province recording the highest prevalence [8]. HIV/AIDS was declared a national disaster in 1988 [9]. Since then, the control of the spread of HIV and AIDS has remained a priority to the Government of Kenya (GOK) [9].

The HIV/AIDS epidemic in Kenya has been characterized as a generalized epidemic, primarily driven by Heterosexual transmission [2]. Over the past decades, impressive strides have been made by the Government of Kenya (GOK) in scaling up HIV prevention, care, and treatment programs in response to the Kenya's HIV/AIDS epidemic. In 2012, national HIV prevalence was estimated to be $5.6 \%$ among Kenyans aged 15-64 years, significantly lower than the HIV prevalence estimate in 2007 of $6.3 \%$ [2].

The Government of Kenya (GOK) developed the Kenya National AIDS Strategic Plan (KNASP III) for the 2009/10-2012/13 implementation period, continuing a comprehensive national response to the epidemic in partnership with civil society, the private sector and development partners [2]. The core of the KNASP III was to provide universal access to essential services which will lead to a reduction in high-risk behavior among the general, HIV infected, key and vulnerable populations; an increase in the proportion of HIV-infected individuals accessing treatment. The current strategy to control AIDS in Kenya KNASP III also aims at mitigating effects of epidemic in households and communities [2]. Even then, in the continued absence of a cure for AIDS or a vaccine against HIV, behaviour change still offers the best promise among the intervention strategies to control the spread of AIDS and minimize its adverse social impacts. People require accurate Knowledge on HIV and AIDS, correct perceptions of personal risk of HIV infection to make behavioral choices that will reduce risk of acquiring and transmitting HIV [6]. Knowledge on HIV and AIDS is also an important prerequisite for prevention in other areas of 
HIV transmission [12]. Accurate Knowledge on HIV and AIDS is invaluable for controlling both felt and perceived stigma as well as the acceptance of new interventions such as Home Based Counseling Test (HBTC), routine Counseling and Tests (CT), Antiretroviral therapy (ART) and Pre-exposure Prophylaxis (PEP) [3].

For more than 20 years, Information Education and Communication (IEC) campaigns in Kenya have aimed to disseminate information about the HIV and AIDS, how AIDS is acquired, and how to prevent new HIV infections [2]. The campaigns also sought to help dispel false information that can lead to fear and blame, and to encourage people to willingly offer support and care to people affected by HIV and AIDS. The current strategy to control AIDS in Kenya KNASP III also aims at mitigating effects of epidemic in households and communities [2]. However, the Kenya Demographic Health Survey (KDHS) report of 2008/09 indicated that comprehensive knowledge about HIV prevention was still low among young people considered sexually active was still below $50 \%$ [6].There has been need therefore to raise awareness in community-level response to HIV and coordination of stakeholders in achieving goals within the national strategy to control the HIV/AIDS epidemic.

The purpose of this study was to assess levels of knowledge on HIV/AIDS and attitudes towards People Living with HIV/AIDS (PLWHAs) and programs to prevent HIV infection in the community of Navakholo, in Western Kenya. Just as in most rural communities in Kenya, the impact of HIV/AIDS in Navakholo is not exceptional. The control AIDS poses a major public health challenge to many rural communities including Navakholo. Navakholo Sub County is one of the seven Sub Counties that make up Kakamega County. Kakamega County to which Navakholo Sub County belongs recorded an HIV prevalence of 5.3\% with an estimated 46,700 persons aged 15-49 years infected with HIV in 2008 [7]. Navakholo Sub County an overtly rural settlement. The inhabitants of the Navakholo are mainly the Luhya ethnic group. The major economic activities in the study area are agriculture, Jua Kali artistry, hawking, businesses etc. Farming of food crops is done mainly to sustain livelihoods. The major stable food crops grown are maize, beans, and cassava. Sugarcane is grown for commercial purposes. Residents also keep livestock including cattle, sheep, goats and local chickens [10].

The justification for the study was that the burden of care and support for people affected by HIV and AIDS (including PLWHAs and Orphans) lies more to the communities than the health care centers. Communities also play an important role in the support and care of PLWHAs through the Home Based Care programs. Moreover, the Ministry of Health $(\mathrm{MOH})$ program of the Kenya Essential Package for Health (KEPH) level one policies for rural communities pursued a strategy to acquire services at the grassroots and even from people close to them in forms of physical, emotional and financial care, the way we can observe it in home based care for HIV/AIDS [2]. It is therefore important to evaluate community levels of knowledge and attitudes on HIV and AIDS in order to tailor communication efforts and enhance the reach of new interventions. Accurate knowledge on HIV and AIDS is more likely to make behavioral change a lot easy.

\section{Methods}

The study adopted a cross-sectional survey research design that mainly used quantitative data collection methods. Structured questionnaires were developed and validated in consultation with professionals from the School of Public Health of Moi University in Kenya in May, 2009. The sample size was determined using the Fischer et al formula $\mathrm{n}=\mathrm{Z}^{2} \mathrm{pq} / \mathrm{d}^{2}$ and a sample size of 384 was obtained and used. The study protocol received approval of the Institutional Ethics and Research Committee (IREC) of Moi University.

The study site (East Bunyala) was randomly selected from the three locations of Navakholo Sub County. This was followed by a random selection of one Sub-location (Sivilie sub location) from the two sub-locations of East Bunyala location. Lists of all the households within Sivilie sub-location were obtained from the respective village elders. The researcher then mapped and assigned numbers to the households creating a complete list of all the households in each village. This was done with the assistance of the village elders. Ballot sheets were then assigned numbers corresponding to each household, from the first to the last household in each of the eleven villages of Sivilie sub location. Using the numbered ballot sheets, households were randomly selected proportionately from each of the 10 villages of Sivilie sub-location, and the head of each selected household was interviewed. In situations where the household head could not be reached (such as those who were in employment far away from their homes), the wife of the household head was considered as his representative and was subsequently interviewed. Similarly, widows of selected $(\mathrm{HH})$ were considered to be household heads and were therefore interviewed. And in situations where the household head or their representatives were available but not present at the time of the visit by the research team, appointments were booked and two follow up visits made to meet the respondent. Fortunately, upon the two revisits, these respondents were traced and interviewed. Using this procedure, 198 male and 186 female respondents were interviewed.

All the respondents participated voluntarily and completed questionnaire anonymously with the help of trained research assistants. The questionnaire took the subjects an estimated 50 minutes to complete. Table 1 below shows the distribution of households within the villages of Sivilie sub-location as revealed by the lists obtained from the respective village elders 
Table 1. Distribution of households within villages in the study area in Navakholo

\begin{tabular}{ccc}
\hline Village & No. of Households & $\begin{array}{c}\text { Number of respondents by } \\
\text { proportions selected for study. }\end{array}$ \\
\hline Sivilie & 86 & 14 \\
Sikubale & 100 & 15 \\
Muregu & 515 & 79 \\
Sengeteti & 79 & 13 \\
Chekata & 817 & 128 \\
Uyaya & 301 & 38 \\
Makhima & 287 & 48 \\
Natunyi & 121 & 21 \\
Musaga & 81 & 13 \\
Mukhuyu & 88 & 15 \\
\hline Total & 2475 & 384 \\
\hline
\end{tabular}

Source: Field Data, 2009.

Knowledge on HIV/AIDS and attitudes towards PLWHAs and programs to prevent HIV infection data was collected from 384 House Hold heads in Navakholo in Western Kenya in survey conducted for Two months from June to July, 2009.

Data was entered, coded, and analysed using SPSS computer software program Version 18. Descriptive statistics and Analysis of Variance (ANOVA) were used analyse data. Level of knowledge on HIV/AIDS was determined using a scale of 20 questions. The questions tested on the cause of AIDS, Signs and symptoms of AIDS, modes of transmission of HIV, practices used to prevent contracting of AIDS and common misperceptions about HIV/AIDS. Responses to these question items were scored. Mean scores and standard deviations were derived. For the purpose of easy comparison, these scores were also expressed as percentages.

Attitude towards PLWHAs and programs to prevent HIV infection was determined from responses of questions using feelings on a 5 point Likert scale of responses i.e. 'strongly disagree', 'disagree' undecided', 'agree' and 'strongly agree'. Analysis was by determining score values for responses in agreement with the positive attitude to the question asked. Responses were also scored. The result was an attitude scale with scores ranging from 10 points (very poor attitude) to 20 points (most favorable attitude). Responses to these question items were scored. Mean scores and standard deviations were derived. For the purpose of easy comparison, these scores were also expressed as percentages. A score of $15(60 \%)$ was used as the cutoff point to determine the type of attitude each respondent had.

\section{Study Findings}

\section{Socio-demographic Characteristics of Respondents}

$179(46 \%)$ of the respondents were aged between 33-40 years. (Mean 39.5 years; Median 38 years). 11 (2.9\%) of the respondents were aged below 18; these were wives of household heads and were therefore considered eligible to give information on behalf of their husbands who were not available at the time of study. Respondents were mainly of one ethnic affiliation, the Banyala $(62 \%)$. Notable also is that the proportion of illiterate respondents was high $(30.5 \%)$, and that more than two-thirds $(69.5 \%)$ of the respondents were unemployed.

Table 2 below presents a summary of the Socio-demographic characteristics of respondents.

Table 2. Socio-demographic characteristics of respondents

\begin{tabular}{|c|c|c|c|}
\hline Variable & Definitions & Count & Percenta \\
\hline \multirow{3}{*}{ Gender } & Male & 198 & $51 \%$ \\
\hline & Femal & 186 & $49 \%$ \\
\hline & Totals $(\mathrm{N})$ & 384 & $100 \%$ \\
\hline \multirow{6}{*}{$\begin{array}{c}\text { Age (in } \\
\text { completed years). }\end{array}$} & Below 18 & 11 & $2.9 \%$ \\
\hline & $18-25$ & 73 & $18.9 \%$ \\
\hline & $26-32$ & 53 & $13.8 \%$ \\
\hline & $33-40$ & 179 & $46.8 \%$ \\
\hline & 41 and above & 68 & $17.7 \%$ \\
\hline & Totals $(\mathrm{N})$ & 384 & $100 \%$ \\
\hline \multirow{5}{*}{ Marital status. } & Single & 2 & $0.52 \%$ \\
\hline & Married & 346 & $90.1 \%$ \\
\hline & Divorced & 11 & $2.9 \%$ \\
\hline & Widowed & 25 & $6.5 \%$ \\
\hline & Totals $(\mathrm{N})$ & 384 & $100 \%$ \\
\hline \multirow{6}{*}{$\begin{array}{l}\text { Religious } \\
\text { Affiliation }\end{array}$} & Catholics & 115 & $30 \%$ \\
\hline & Muslims & 42 & $11 \%$ \\
\hline & Protestants & 207 & $54 \%$ \\
\hline & Traditional & 15 & $4.0 \%$ \\
\hline & Others & 5 & $1 \%$ \\
\hline & Totals (N) & 384 & $100 \%$ \\
\hline \multirow{7}{*}{ Ethnic affiliation. } & Bunyala & 234 & $60.9 \%$ \\
\hline & Wanga & 42 & $10.9 \%$ \\
\hline & Kabrasi & 44 & $11.5 \%$ \\
\hline & Bukusu & 20 & $5.2 \%$ \\
\hline & Others & 44 & $11.45 \%$ \\
\hline & Totals (N) & 384 & $100 \%$ \\
\hline & None & 117 & $30.5 \%$ \\
\hline \multirow{4}{*}{$\begin{array}{l}\text { Highest-Level of } \\
\text { education } \\
\text { attained. }\end{array}$} & Primary school & 159 & $41.4 \%$ \\
\hline & Secondary school & 79 & $20.7 \%$ \\
\hline & Tertiary & 29 & $7.5 \%$ \\
\hline & Totals (N) & 384 & $100 \%$ \\
\hline \multirow{4}{*}{$\begin{array}{l}\text { Employment } \\
\text { status. }\end{array}$} & None & 267 & $69.5 \%$ \\
\hline & Self employed & 82 & $21.3 \%$ \\
\hline & Formal employment & 35 & $9.1 \%$ \\
\hline & Totals $(\mathrm{N})$ & 384 & $100 \%$ \\
\hline
\end{tabular}

Source: Field Data, 2009.

\section{Level of Knowledge on HIV and AIDS}

Majority 357 (92.9\%) of the respondents had a high Level of knowledge on AIDS (Table 3). The mean HIV/AIDS knowledge score of the respondents was 16.0 ( $\pm 2.3 \mathrm{SD})$ out of 20; however, further analysis of responses on knowledge questions revealed some differences and gaps in knowledge on HIV transmission and AIDS. Differences were noted when we compare knowledge on HIV/AIDS for the variables gender, level of education and age of respondents. Analysis of Variance (ANOVA) was used to determine statistical significance between the differences noted.

Table 3. Level of knowledge on HIV and AIDS.

\begin{tabular}{ccc}
\hline Level of knowledge & Frequency & Percent (\%) \\
\hline $\begin{array}{c}\text { Respondents with High level of } \\
\text { knowledge }\end{array}$ & 357 & 92.9 \\
$\begin{array}{c}\text { Respondents with Low level of } \\
\text { knowledge }\end{array}$ & 27 & 7.1 \\
\hline Totals (N) & 384 & 100.0 \\
\hline
\end{tabular}

Source: Field Data 


\section{Knowledge on HIV/AIDS and Gender Disparity}

Both the male and female respondents had accurate information regarding HIV/AIDS. The only observable differences on knowledge across gender were on issues of vertical transmission of HIV, susceptibility to HIV infection, and modes of HIV transmission. Female respondents appeared more knowledgeable on facts about vertical transmission of HIV, Susceptibility to HIV infection and Modes of transmission of HIV than their male counterparts (Table 4)

\section{HIV/AIDS Knowledge and Level of Education}

Respondents who have higher levels of education appeared more knowledgeable of facts concerning HIV/AIDS. For instance they all know that; there is no cure HIV/AIDS, prevention of AIDS by condom use and abstinence, HIV transmission modes, AIDS symptoms and susceptibility to HIV infection. This situation is not true for people with lower formal education. For example, $4 \%$ of people without formal education and $5 \%$ of people with primary education do not know that there is no cure for HIV/AIDS. In addition $20 \%$ of people without education and $11 \%$ of people with primary education state that by looking at a person, one can tell they are infected with HIV; while none amongst people with secondary and tertiary education do agree with this fact. These differences are significantly observable going by the difference in the percentages of responses to knowledge questions. Further, $42 \%$ of respondents who did not have a formal education and $20 \%$ with primary education believed that one can be infected with HIV by mosquito, flee or bedbug bites while none amongst those with tertiary education held this belief.

\section{HIV/AIDS Knowledge by Age}

There wasn't much difference in knowledge between people aged 40 years and below, and those aged above 40 years with regard to knowledge on facts about absence of cure for HIV/AIDS, HIV prevention and transmission. However, we observe significant differences across the two age brackets when we consider knowledge on vertical transmission, the difference between HIV and AIDS, AIDS symptoms and susceptibility to HIV infection. Findings of the study revealed that people who were perceived by the study as sexually active i.e. the young adults ( 40 years of age and below) appear to be less knowledgeable than those seen to be fairly less sexually active (above 40 years) with regard to the variables of Vertical transmission of HIV, Difference between HIV infection and AIDS, Signs and symptoms of AIDS and Susceptibility to HIV infection. Table 5 below summarizes the differences in Knowledge on HIV/AIDS across Age Categories.

Table 4. Differences in Knowledge on HIV/AIDS across gender.

\begin{tabular}{|c|c|c|c|}
\hline Variable. & \multicolumn{2}{|c|}{ Frequency of correct responses } & $\begin{array}{l}\text { Level of significance on } \\
\text { difference. }\end{array}$ \\
\hline Knowledge on; & Males $(n=198)$ & Females $(n=186)$ & \\
\hline Vertical transmission of HIV & $59(30 \%)$ & $93(50 \%)$ & .001 \\
\hline Susceptibility to HIV infection & $40(20 \%)$ & $56(30 \%)$ & .010 \\
\hline Modes of transmission of HIV & $137(69 \%)$ & $167(90 \%)$ & .001 \\
\hline
\end{tabular}

Source: Field Data, 2009

Table 5. Differences in Knowledge on HIV/AIDS across Age Categories

\begin{tabular}{|c|c|c|c|}
\hline Variable. & \multicolumn{2}{|c|}{ Frequency of correct responses } & $\begin{array}{c}\text { Level of significance on } \\
\text { difference. }\end{array}$ \\
\hline Knowledge on; & $\leq 40$ years $(n=316)$ & $\geq 40$ years $(n=68)$ & \\
\hline Vertical transmission of HIV & $183(58 \%)$ & $63(93 \%)$ & .008 \\
\hline Difference between HIV infection and AIDS. & $221(70 \%)$ & $62(91 \%)$ & .010 \\
\hline Signs and symptoms of AIDS & $79(25 \%)$ & $43(63 \%)$ & .007 \\
\hline Susceptibility to HIV infection & $54(17 \%)$ & $41(60 \%)$ & .001 \\
\hline
\end{tabular}

Source: Field Data, 2009 


\section{Attitudes towards PLWHAs and Programs to Control HIV/AIDS}

Two-thirds -253 (66\%) of the respondents appeared to hold positive attitude towards PLWHAs and programs to control AIDS. However, further analysis revealed varied opinions on certain issues key to stigma mitigation in the community. Analysis of Variance (ANOVA) was used to determine statistical significance between the differences noted. Table 6 below summarises the frequency on the distribution of attitudes towards PLWHAs and programs to control AIDS among respondents.

Table 6. Distribution of Attitudes towards PLWHAs and programs to control AIDS.

\begin{tabular}{ccc}
\hline Variable Attitude & Frequency & Percent \\
\hline Respondents with positive attitude & 253 & 66 \\
Respondents with negative attitude & 131 & 34 \\
\hline Total $(\mathrm{N})$ & 384 & 100.0 \\
\hline
\end{tabular}

Source: Field Data, 2009

\section{Attitude towards PLWHAs and Programs to Control AIDS across Gender}

Both male and female respondents had similar feelings regarding HIV/AIDS and programs to prevent HIV infection. Male and female respondents differ in opinion about the three attitude variables regarding HIV/AIDS (Table 7). Female's respondents appeared more willing to disclose that AIDS had caused death of a relative and would also be more willing to take care of a family member found to be suffering from AIDS at home. These differences across gender are however, not strongly significant.

Table 7. Differences across Gender in Attitudes towards PLWHAs and programs to control AIDS

\begin{tabular}{|c|c|c|c|}
\hline Variable. & \multicolumn{2}{|c|}{$\begin{array}{c}\text { Frequency of respondents displaying } \\
\text { positive attitude responses }\end{array}$} & $\begin{array}{c}\text { Level of significance on } \\
\text { difference. } \\
(p \text {-value at } 0.05)\end{array}$ \\
\hline Attitude statement that; & Males $(n=198)$ & $\begin{array}{c}\text { Females } \\
(n=186)\end{array}$ & \\
\hline $\begin{array}{l}\text { One should disclose that AIDS is cause of } \\
\text { death when a community member dies. }\end{array}$ & $133(67 \%)$ & $162(87 \%)$ & .005 \\
\hline AIDS the worst Disease & $141(71 \%)$ & $162(87 \%)$ & .013 \\
\hline $\begin{array}{l}\text { Willingness to care for a family member } \\
\text { found to be suffering for AIDS at home. }\end{array}$ & $83(42 \%)$ & $126(68 \%)$ & .008 \\
\hline
\end{tabular}

Source: Field Data, 2009

\section{Level of Education and Attitude towards PLWHAs and Programs to Control AIDS}

There wasn't much difference between people with a higher education and those with a lower education over some of their perceptions about HIV/AIDS (Higher education here implies having at least secondary school education). More people with a higher education were of the opinion that everybody should be tested for HIV. This same pattern applies to disclosure of one's serostatus i.e. If one is infected with HIV, he/she should not keep this as a secret from the community where one lives, and that persons infected with HIV should be allowed to continue working. These differences in attitude across levels of education are quite significant. Table8 below summarises study findings on Level of Education and Attitudes towards PLWHAs and programs to control AIDS.

Table 8. Differences in Levels of Education and Attitudes towards PLWHAs and programs to control AIDS

\begin{tabular}{cccc}
\hline Variable. & $\begin{array}{c}\text { Frequency of respondents who displayed } \\
\text { positive attitude responses }\end{array}$ & $\begin{array}{c}\text { Level of significance on } \\
\text { difference. } \\
(\boldsymbol{p} \text {-value at 0.05) }\end{array}$ \\
\hline Attitude statement that; & $\begin{array}{c}\text { Below secondary } \\
\text { education(n=278) }\end{array}$ & $\begin{array}{c}\text { Secondary education } \\
\text { and above. (n=108) }\end{array}$ & \\
\cline { 2 - 3 } $\begin{array}{c}\text { Everybody should be tested for HIV. } \\
\text { One should disclose his/her HIV serostatus }\end{array}$ & $\mathbf{2 0 0}(72 \%)$ & $\mathbf{1 0 4}(96 \%)$ & .003 \\
$\begin{array}{c}\text { Persons infected with HIV should be allowed } \\
\text { to continue working }\end{array}$ & $\mathbf{2 0 0}(72 \%)$ & $\mathbf{9 9}(92 \%)$ & .002 \\
\hline
\end{tabular}

Source: Field Data, 2009

\section{Role of Government for PLWHAs}

To further assess attitudes towards PLWHAs, respondents had been asked what they considered as the most important thing the government should do for PLWHAs. Most respondents-247(64\%) felt the Government should provide treatment and help relative take care of PLWHAs (Figure1). However, 42 respondents (11\%) felt that the government should either isolate PLWHAs or not be involved at all. 


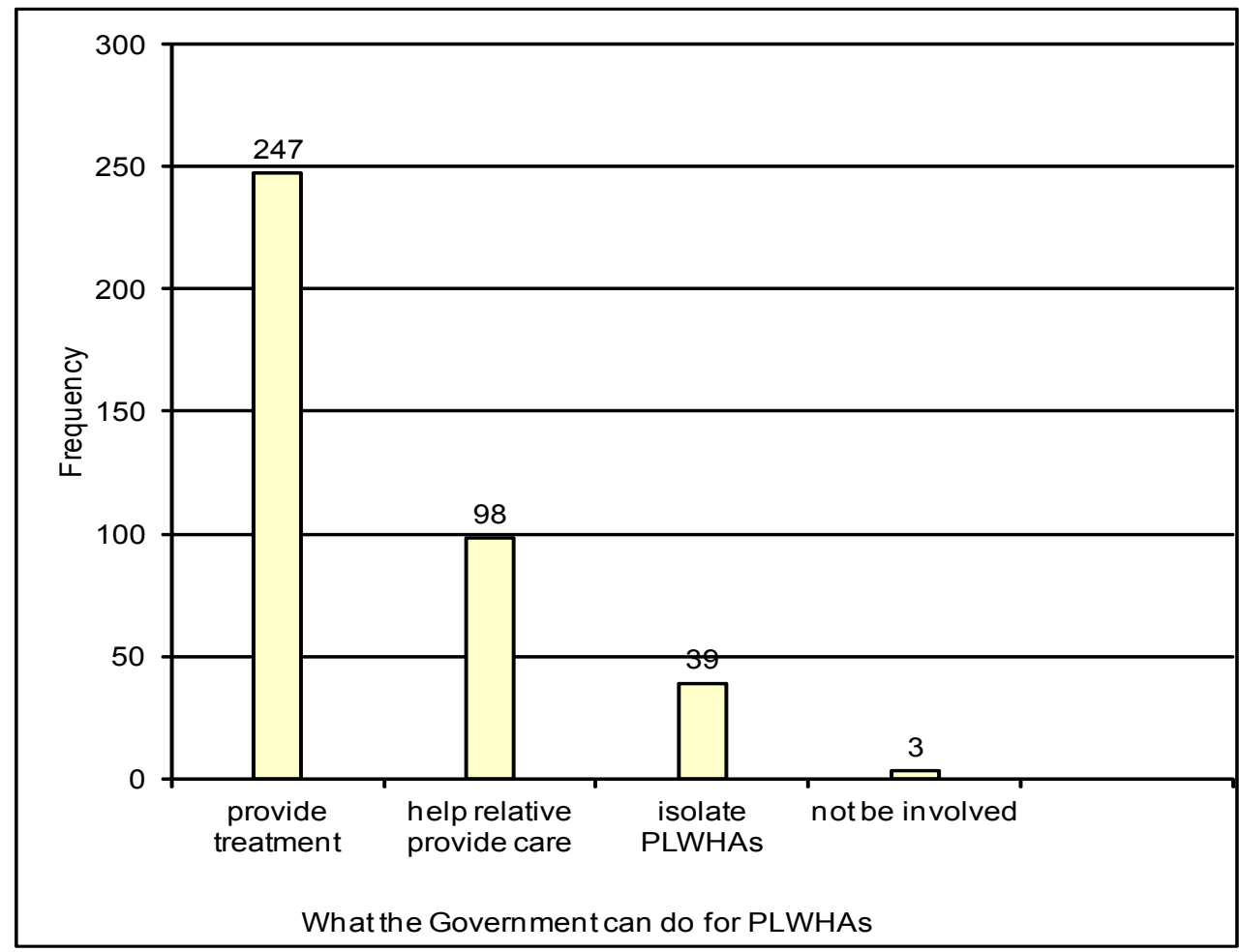

Figure 1. Role of the Government for PLWHAs (Source: Field Data, 2009)

\section{Perceptions on the Risk of contracting AIDS}

Majority of the respondents (87\%) perceived themselves as having a high chance (risk) to contract AIDS. Less than 5\% felt that there was either little or no risk of contracting AIDS. Figure 2 below summarises frequencies of their responses.

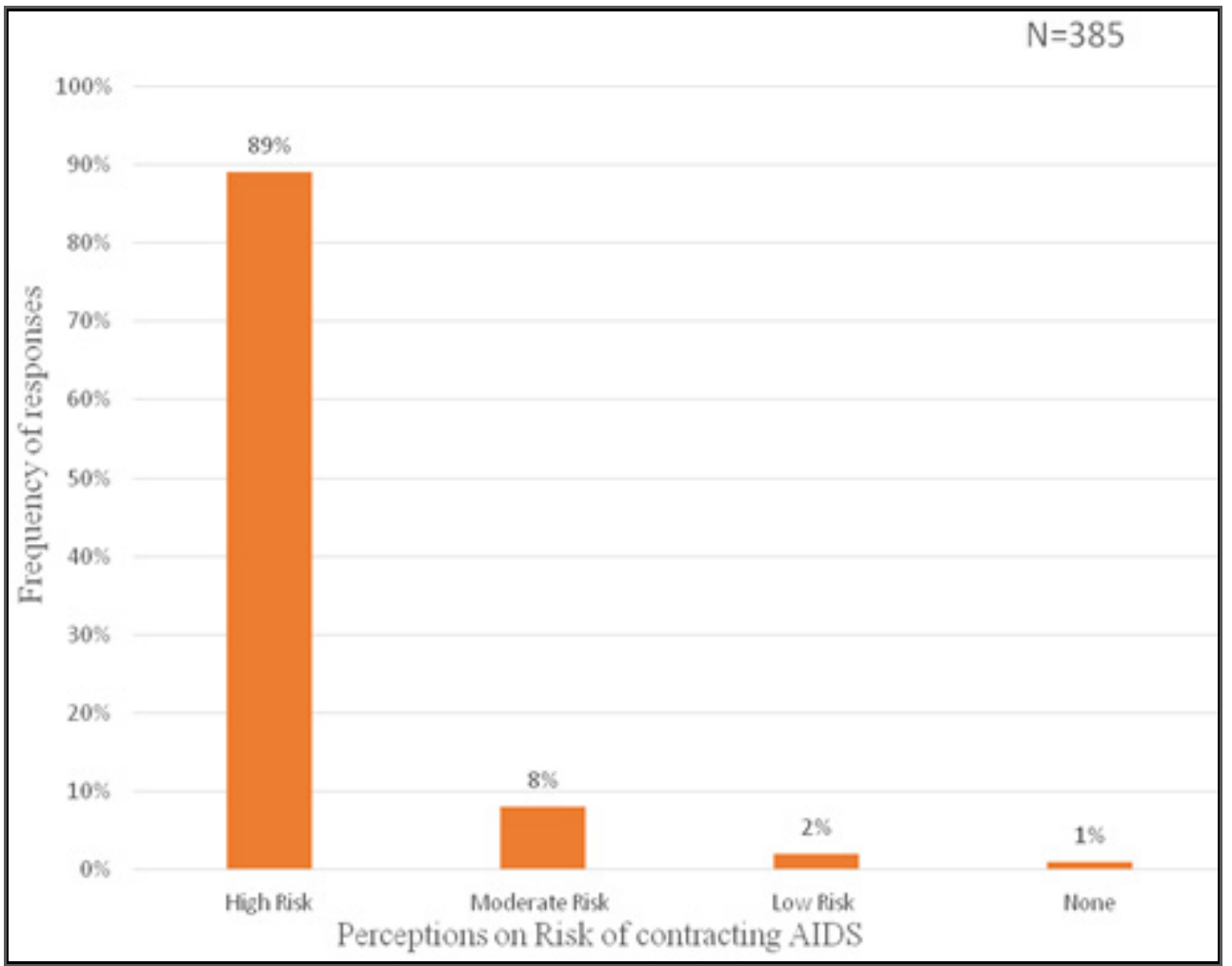

Figure 2. Perceptions on the Risk of contracting AIDS (Source: Field Data, 2009) 


\section{Discussion}

Generally, the level of knowledge on HIV and AIDS recorded for members of the study community was high. The level of knowledge on HIV/AIDS recorded for members of the study community is higher than that reported by the KAIS [7] and the KDHS report [6]. This high level of knowledge can be attributed to the numerous AIDS awareness campaigns that members of this community are exposed to through the IEC programs, media, seminars or trainings. However, some gaps in knowledge and certain misconceptions about HIV transmission were also evident. Women were significantly more knowledgeable than men on certain aspects of knowledge on HIV and AIDS ( $p$-values for vertical transmission is .001 , for susceptibility is .010 and for modes of HIV transmission is .001). Women appear more knowledgeable in these aspects about HIV and AIDS probably because women are regular attendants of social gatherings such as religious services, weddings and funerals where HIV/ and AIDS information is often delivered; and also because many women get more information about HIV/AIDS when they attend antenatal clinics.

With this high levels of knowledge on HIV and AIDS, it is expected that the community utilizes this advantage to embrace behavior change, mitigate stigma and discrimination associated with HIV/AIDS. This is because knowledge about HIV and AIDS although insufficient, is a necessary condition for behaviour change including acceptance of PLWHAs and the provision of social support for people affected by the disease. Gaps in knowledge and misconceptions such as those revealed in this study have clear negative implications and reduce the potential to lower AIDS related stigma amongst a sizeable population of the community $[7,8]$. For instance, community members who do not know the difference between HIV infection and having AIDS may hold discriminatory behavior since they are unlikely to consider treatment options available or the positive effects of such treatment options; also, failure to understand that it is possible for an HIV positive mother to give birth to an HIV negative baby may intensify stigma in the community because it may cause some people to shun antenatal AIDS prevention programmes such as PMTCT [10]; Similarly, failure by some community members to understand that everybody is susceptible to HIV infection can lead certain groups of individuals to believe they are invincible to discriminate upon those they perceive to be vulnerable [13].

Attitude towards PLWHAs and programs to prevent HIV infection can generally be described as poor. Key issues necessary for stigma mitigation scored poorly. Higher levels of education (secondary and tertiary) are linked to positive attitudes about HIV/AIDS and programs to prevent HIV infection; this is probably because people with higher education levels can easily comprehend some difficult aspects about HIV transmission and AIDS [3]. Thus they easily give correct or expected views.
Attitude towards PLWHAs and Programs to prevent HIV Infection has important implications because attitude has a major influence over behavior change A positive attitude towards PLWHAs and programmes to prevent HIV infection is also necessary for stigma mitigation and provision of social support.

For instance, a large proportions of the study population (90\%) were willing to discuss HIV/AIDS freely and are an asset to stigma mitigation because this section of the community has beaten silence and denial, acknowledge the existence of the disease and can therefore appreciate need to learn about HBC and the need to provide social support for people affected by HIV/AIDS. Conversely, negative attitudes displayed by the study population signify serious impediments to community efforts to mitigate AIDS related stigma and control the disease. For instance, a large proportions $(66 \%)$ of community members harbor the feeling that getting infected with HIV/AIDS is like a death sentence; these may be the perpetrators of AIDS stigma; because such people may never wish to disclose their serostatus and are therefore unlikely to enroll into HIV/AIDS care programmes in the community including those that aim at reducing stigma to forge way for social support. Similarly, the many community members (48\%) that have the attitude that HIV/AIDS is the worst disease are likely to have poor regard for PLWHAs and are therefore unlikely to provide social support for PLWHAs. Negative attitude revealed by this study are an indicator that certain aspects about HIV infection and AIDS may not have been clearly understood by some community members.

\section{Conclusions}

Based on the study findings and the discussion in the preceding section, the study concludes that some members of the community in Navakholo still lack certain aspects of knowledge on HIV/AIDS that is necessary for behavioral change and HIV/AIDS stigma mitigation. Many members of the Navakholo community have negative attitudes in certain key issues necessary for reduction of AIDS related stigma and the control of the spread of AIDS. The study therefore recommends that intensive HIV/AIDS education should be given to members of the community in an effort to help improve knowledge bases so as to fill gaps in knowledge and to eliminate misconceptions such as those noted, improve on attitudes and encourage families to care for PLWHAs at home through the Home Based Care (HBC), and also to encourage members of this community to disclose their serostatus. This education can be given by Community Based Health Organizations (CBHOs), Constituency AIDS Committee and Community Health personnel in workshops, seminars, and trainings, or social gatherings such as weddings, funerals, religious congregation meetings and chief's public gatherings. 


\section{REFERENCES}

[1] United Nations Program on HIV/AIDS -UNAIDS, (2013). Report on the Global AIDS epidemic 2013. Geneva: UNAIDS; 2013.

[2] Ministry of Health (MOH) (2013). Kenya National AIDS Strategic Plan (KNASP) 2009/10-2012/13. Available at http://www.nacc.or.ke. Accessed on 12/9/11

[3] World Health Organization -WHO (2010). 'Towards universal access: Scaling up priority HIV/AIDS interventions in the health sector the country- Progress report 2010

[4] World Health Organization WHO (2008) 'Towards Universal Access: Scaling up priority HIV/AIDS interventions in the health sector: Progress report 2008

[5] United Nations General Assembly Special Session on HIVUNGASS (2008) 'Country Report - Kenya' Kenya Office of the President, Ministry of Special Programmes

[6] Joint United Nations Programme on AIDS -UNAIDS. (2010) 'AIDS in Africa', Country by Country; African Development Forum, 20 Avenue Appia-1211 Geneva 27, Switzerland.

[7] National AIDS and STI Control Program-NASCOP, (2008). Ministry of Health (MOH), Kenya. July 2008. Kenya AIDS Indicator Survey 2007: Preliminary Report. Nairobi, Kenya

[8] National AIDS Control Council -NACC (2009). 'Kenya National HIV and AIDS Strategic Plan 2005/06 - 2009/10'

[9] Kenya Demographic and Health Survey-KDHS (2009).
Preliminary Report p 121-132.

[10] Government of Kenya -GOK (2003). Kakamega District Development Plan, (2002 - 2008). Nairobi, Government printers Pg. $6-15$.

[11] International Treatment Preparedness Coalition (ITPC) (2007).'Missing the target: Improving AIDS drug access and advancing health care for all'

[12] Turan, J. M., Miller, S., Bukusi, E. A., Sande, J., \& Cohen, C. R. (2008). HIV/AIDS and Maternity care in Kenya: how fears of stigma and discrimination affect uptake and provision of labor and delivery services. AIDS Care, 20(8), 938-945.

[13] Human Rights Watch (2009). 'Letter to Kenyan Minister of Public Health and Sanitation concerning Home-based HIV testing and counseling.'

[14] Teddlie, C. \&Tashakkorri, A. (Eds.) (2010). SAGE Handbook of Mixed Methods in Social Research and Behavioural research $\left(2^{\text {nd }} E d,\right)$ Thousand Oaks, CA: Sage

[15] Mukhwana E. S, Ngaira J.K, Mutai C. (2015). Determinants of Uptake and Utilization of National Hospital Insurance Fund Medical Cover by People in the Informal Sector in Kakamega County, Kenya. Universal Journal of Public Health 3(4): 169-176.

[16] Mukhwana E. S, Ngaira J.K, Mutai C. (2015). Strategies to Enhance Utilization of National Hospital Insurance Fund Scheme Medical Cover by Informal Sector Populations in Kakamega County, Kenya .Universal Journal of Public Health 3(5): 180-186. 